\title{
Lack of c-kit (CD117) expression in CD30 + lymphomas and lymphomatoid papulosis
}

\author{
George Z Rassidakis ${ }^{1}$, Georgios V Georgakis ${ }^{2}$, Mauricio Oyarzo ${ }^{1}$, Anas Younes ${ }^{2}$ and \\ L Jeffrey Medeiros ${ }^{1}$ \\ ${ }^{1}$ Department of Hematopathology and ${ }^{2}$ Department of Lymphoma-Myeloma, The University of Texas MD \\ Anderson Cancer Center, Houston, TX, USA
}

\begin{abstract}
c-Kit receptor (CD117) is expressed by erythroid, megakaryocytic, and myeloid precursors and mature mast cells and has been reported to be expressed in CD30 + lymphomas such as Hodgkin's disease and anaplastic large-cell lymphoma. Imatinib mesylate, a well-established inhibitor of bcr-abl tyrosine kinase, and currently used for the treatment of patients with chronic myeloid leukemia, also inhibits c-kit receptor kinase activity. In view of the possible use of imatinib as experimental therapy for patients with c-kit-positive tumors, we assessed c-kit expression in CD30 + cell lines and lymphomas. The cell lines were assessed using multiple methods (RTPCR, flow cytometry, and Western blot). c-Kit expression was also immunohistochemically assessed in 168 CD30 + lymphomas including 87 classical Hodgkin's disease, 63 anaplastic large-cell lymphoma, and 15 cutaneous anaplastic large-cell lymphoma. We also studied 18 cases of lymphomatoid papulosis, a CD30 + lesion closely related to cutaneous anaplastic large-cell lymphoma. Neither c-kit mRNA nor protein was detected in any of the cell lines assessed. Furthermore, treatment with imatinib did not inhibit proliferation of cell lines in vitro. Using immunohistochemistry, only one of $183(0.5 \%)$ lesions was positive for c-kit, the positive case being an ALK-negative anaplastic large-cell lymphoma. Our data demonstrate that expression of c-kit receptor is exceedingly rare among CD30 + lymphomas and lymphomatoid papulosis, suggesting that ckit receptor is unlikely to be an appropriate target for therapeutic options such as imatinib in patients with these tumors.
\end{abstract}

Modern Pathology (2004) 17, 946-953, advance online publication, 23 April 2004; doi:10.1038/modpathol.3800144

Keywords: c-kit; Hodgkin's disease; Anaplastic large-cell lymphoma; lymphomatoid papulosis; imatinib mesylate

The c-kit gene, first identified as the human analog of $\mathrm{v}$-kit, the oncogene of HZ4 feline sarcoma virus, encodes a $145 \mathrm{kDa}$ transmembrane glycoprotein capable of autophosphorylation on tyrosine residues. c-Kit receptor (CD117), henceforth referred to as c-kit in this study, is structurally related to the receptors for macrophage growth factor and platelet-derived growth factor. ${ }^{1}$ C-Kit ligand, also known as stem cell factor (SCF), is capable of promoting cell proliferation of both myeloid and lymphoid hematopoietic progenitors in bone marrow cultures, ${ }^{2}$ mainly by ligand-binding-dependent phosphorylation of tyrosine residues located at the cytoplasmic portion of ckit, thereby initiating signal transduction pathways. ${ }^{3}$

In normal bone marrow, c-kit is expressed by stem cells, most erythroid and megakaryocytic precur-

Correspondence: Dr LJ Medeiros, MD, Department of Hematopathology, Box 72, University of Texas MD Anderson Cancer Center, 1515 Holcombe Blvd., Houston, TX 77030, USA.

E-mail: jmedeiro@mail.mdanderson.org

Received 3 February 2004; revised 3 March 2004; accepted 5 March 2004; published online 23 April 2004 sors, a subset of granulocytic and monocytic cells and mature mast cells. ${ }^{4-6}$ In 1994, Pinto et $\mathrm{al}^{7}$ reported that c-kit is expressed in CD30 + lymphomas, including most cases of anaplastic large-cell lymphoma (ALCL) and approximately $50 \%$ of Hodgkin's disease (HD), but not in other nonHodgkin's lymphomas. Subsequently, c-kit was reported to be expressed and functional in most HD cell lines. ${ }^{8,9}$ However, others ${ }^{10,11}$ have not confirmed these results. In addition, in a preliminary study published as a letter, we could not identify c-kit-positive cases of HD and ALK + ALCL. ${ }^{12}$ Thus, expression and functional status of c-kit in lymphomas remains a controversial issue. Furthermore, expression of c-kit in other CD30-positive lymphomas such as ALK-negative ALCL and cutaneous ALCL, as well as lymphomatoid papulosis, the latter closely related to cutaneous ALCL, is unknown.

Imatinib mesylate (imatinib, STI571, Gleevec ${ }^{\mathbb{B}}$, Novartis Pharma AG, Basel, Switzerland) was first developed as a specific inhibitor of the bcr-abl protein tyrosine kinase ${ }^{13}$ and is clinically used for the treatment of patients with chronic myeloid 
leukemia. ${ }^{14,15}$ Subsequently, imatinib was found to inhibit other receptor tyrosine kinases, including ckit, ${ }^{16,17}$ and was shown to be active against c-kitpositive gastrointestinal stromal tumors. ${ }^{18}$ With previous reports of c-kit expression in $\mathrm{HD}$ and ALCL having obvious therapeutic implications for imatinib or similar chemotherapeutic agents, and yet at variance with our preliminary results, ${ }^{12}$ we decided to assess rigorously for c-kit expression in HD and ALCL cell lines and a large number of CD30 + lymphomas including HD, systemic ALCL and cutaneous ALCL. We also assessed cases of lymphomatoid papulosis. Since, the effect of imatinib in ALCL cells is unknown, we also assessed viability and proliferation of ALCL cell lines after treatment with imatinib.

Our data show that c-kit is not expressed in HD or ALCL cell lines and is rarely expressed in CD30 + lymphomas. Only one lymphoma, an ALK-negative case of ALCL, was c-kit-positive. All cases of lymphomatoid papulosis were negative. Treatment of HD and ALCL cell lines with imatinib did not affect viability or proliferation. These findings suggest that c-kit does not appear to be an appropriate target for investigational therapies in patients with HD or ALCL.

\section{Materials and methods}

\section{Cell Lines}

The panel of cell lines used included five known classical HD cell lines (HD-MYZ, HDLM2, L-428, KM-H2, and L-1236) (purchased from DSMZ, Braunschweig, Germany), two novel classical HD cell lines recently established at our institution (MDA-V and MDA-E), and five ALK-positive ALCL cell lines (Karpas 299, SR-786, SU-DHL-1, JB-6, and TS-G1). The gastrointestinal stromal tumor cell line ST-882 (a gift from Dr J Trent, Houston, TX, USA) and the megakaryoblastic leukemia cell line MO7e (a gift from Dr M Andreeff, Houston, TX, USA) served as positive controls for c-kit expression. The cell lines were maintained in RPMI 1640 medium supplemented with $1 \%$ nonessential amino acids, $10 \%$ fetal calf serum (Invitrogen Corporation, Grand Island, NY, USA), and 1\% streptomycin-penicillin. Cells were incubated at $37^{\circ} \mathrm{C}$ in a humidified atmosphere containing $5 \% \mathrm{CO}_{2}$. Paraffin-embedded cell blocks of cell pellets fixed in $10 \%$ buffered formalin were also prepared.

\section{RNA Extraction and Reverse Transcription-Polymerase Chain Reaction}

RNA was extracted using the RNAqueous ${ }^{\circledR}$ kit (Ambion Inc, Austin, TX, USA) according to the manufacturer's instructions. cDNA was synthesized using the Superscript ${ }^{\mathrm{TM}}$ First Strand Synthesis System for reverse transcription (RT)-polymerase chain reaction (PCR) (Invitrogen Life Technologies, Carlsbad, CA, USA) according to the manufacturer's instructions. The quality of cDNA was tested by PCR using primers specific for the $18 \mathrm{~S}$ cDNA. For RTPCR amplification of c-kit, we used the following primers: 5'-AACGACACGCTGGTCCGCTG-3' (forward), and 5'-GTACACAGAACTAGACACATC- $3^{\prime}$ (reverse). We also tested another set of primers and conditions as reported by Aldinucci et al. ${ }^{8}$

\section{Southern Blot Analysis of the RT-PCR Products}

Following amplification, $10 \mu \mathrm{l}$ of RT-PCR products were run on a $1.5 \%$. agarose gel, transferred to Hybond $\mathrm{N}+$ nylon membranes (Amersham Pharmacia Biotech, Inc., Piscataway, NJ, USA) and hybridized with an internal oligonucleotide, 5' CCCAGAAGTGACCAATTATTCCCT- ${ }^{\prime}$. This probe was labeled for $2 \mathrm{~h}$ at $37^{\circ} \mathrm{C}$ according to the manufacturer's instructions (Amersham Pharmacia Biotech). After hybridization, the membrane was incubated with detection reagent for $5 \mathrm{~min}$ at room temperature, drained, and placed in a film cassette for autoradiography.

\section{Western Blot Analysis}

Cells in log-phase growth were collected and lysed at $4{ }^{\circ} \mathrm{C}$ in lysis buffer with appropriate protease and phosphatase inhibitors. Western blot analysis was performed using standard methods and $50 \mu \mathrm{g}$ of total protein from each cell line. Two commercially available polyclonal antibodies specific for c-kit were used: A4502 (DAKO, Carpinteria, CA, USA), and C-19 (Santa Cruz Biotechnology, Santa Cruz, CA, USA). Both antibodies were raised against a peptide from the cytoplasmic C-terminal part of human c-kit.

\section{Flow Cytometry}

Cells from all seven HD and one ALCL cell lines (Karpas 299) were analyzed for c-kit expression by flow cytometry with a phycoerythrin-conjugated monoclonal antibody specific for c-kit (clone 104D2, BD Biosciences Pharmingen, San Diego, CA, USA) using standard protocols and a FACScan instrument (Becton Dickinson, San Jose, CA, USA). The MO7e cell line served as a positive control for c-kit expression in these experiments.

Annexin V/propidium iodide (PI) staining was also performed using flow cytometry according to the manufacturer's guidelines. Briefly, $0.5 \times 10^{6}$ cells were washed in ice-cold PBS without $\mathrm{Ca}^{2+}$ or $\mathrm{Mg}^{2+}$ (Life Technologies). The cells were then resuspended in $100 \mu \mathrm{l}$ of binding buffer and incubated with $5.0 \mu \mathrm{l}$ of PI and $2.0 \mu \mathrm{l}$ of annexin V-fluorescein isothiocynate for $15 \mathrm{~min}$ in the dark at room temperature. Flow cytometric analysis was 
immediately performed using a FACSCalibur Instrument (Becton Dickinson).

\section{Immunohistochemistry}

c-Kit expression was assessed immunohistochemically in 87 classical HD (66 nodular sclerosis, 21 mixed cellularity), 63 ALCL (30 ALK-positive, 33 ALK-negative), and 15 cutaneous ALCL. We also assessed 18 cases of lymphomatoid papulosis, a disorder closely related to cutaneous ALCL. All lesions were diagnosed at The University of Texas MD Anderson Cancer Center. The histologic diagnoses of the lymphomas were based on criteria specified in the World Health Organization (WHO) classification. ${ }^{19}$ The distinction between cutaneous ALCL and lymphomatoid papulosis was based on clinical data.

Full tissue sections and tissue microarrays ${ }^{20}$ that included three or four tumor cores were assessed using an immunohistochemical method as described elsewhere. ${ }^{21}$ Of the most widely used commercially available antibodies against c-kit, we used the A4502 polyclonal antibody from DAKO, since a recent validation study reported optimal immunohistochemical results and high specificity using this reagent. ${ }^{22,23}$ Full tissue sections obtained from a gastrointestinal stromal tumor were used as a positive control. In addition, occasional monocytes and mast cells seen in many HD and ALCL tumors served as internal positive controls for c-kit expression.

\section{Imatinib Treatment and Proliferation Assay}

A panel of cell lines including Karpas 299, SUDHL-1, L-428, HD-LM2, and HD-MyZ were treated in 12well plates with imatinib using different concentrations of drug $(0.05,0.5$, and $5 \mu \mathrm{M}) .{ }^{11}$ At 24 and $48 \mathrm{~h}$ a tetrazolium compound [3-(4,5-dimethylthiazol-2yl)-5-(3-carboxymethoxyphenyl)-2-(4-sulfophenyl)-2Htetrazolium, MTS] was added to each well using the CellTiter 96 ${ }^{\circledR} \mathrm{AQ}_{\text {ueous }}$ kit (Promega, Madison, WI, USA) according to the manufacturer's instructions and light absorbance was measured using a $\mu$ Quant spectrophotometer (BIO-TEK Instruments Inc., Winooski, VT, USA). The MTS assay was performed twice and the mean numbers of proliferating and viable cells were calculated at 24 and $48 \mathrm{~h}$ after treatment with imatinib.

\section{Results}

\section{c-kit RNA Levels in HD and ALCL Cell Lines}

Table 1 summarizes the results for c-kit expression in HD and ALCL cell lines at the RNA level. Using RT-PCR and a set of primers we designed, all HD and ALCL cell lines were found to be negative for $c$-kit RNA (Figure 1). Southern blot transfer and hybridization using a probe specific for c-kit revealed no bands observed in HD or ALCL cell lines. Only the
Table 1 Expression of c-kit protein in HD and ALCL cell lines and tumors

\begin{tabular}{|c|c|c|c|c|}
\hline \multirow[t]{2}{*}{ Cell lines } & \multirow{2}{*}{$\begin{array}{c}R N A \\
\text { level } \\
\text { RT-PCR }\end{array}$} & \multicolumn{3}{|c|}{ Protein level } \\
\hline & & $F C$ & $W B$ & IHC \\
\hline \multicolumn{5}{|l|}{ HD cell lines } \\
\hline HD-MYZ & _ & - & _- & _- \\
\hline HDLM2 & - & - & - & - \\
\hline $\mathrm{L}-428$ & _- & - & _- & _- \\
\hline KM-H2 & - & - & - & - \\
\hline L-1236 & - & - & - & - \\
\hline MDA-V & _- & - & _- & - \\
\hline MDA-E & - & - & - & - \\
\hline \multicolumn{5}{|l|}{ ALCL cell lines } \\
\hline Karpas 299 & - & - & - & - \\
\hline SR-786 & - & ND & - & - \\
\hline SU-DHL-1 & - & ND & - & - \\
\hline JB-6 & ND & ND & _ & _ \\
\hline TS-G1 & ND & ND & - & - \\
\hline \multicolumn{5}{|l|}{ Control cell lines } \\
\hline ST-882 & + & + & + & + \\
\hline MO7e & + & + & + & + \\
\hline \multirow[t]{2}{*}{ Tumors } & \multicolumn{4}{|c|}{$I H C$} \\
\hline & \multicolumn{2}{|c|}{ c-Kit positive } & \multicolumn{2}{|c|}{$\%$} \\
\hline Classical HD $(n=87)$ & \multicolumn{2}{|c|}{$0 / 87$} & \multicolumn{2}{|c|}{0} \\
\hline ALK+ALCL $(n=30)$ & \multicolumn{2}{|c|}{$0 / 30$} & \multicolumn{2}{|c|}{0} \\
\hline ALK-ALCL $(n=33)$ & & \multicolumn{2}{|c|}{3} \\
\hline Cutaneous ALCL $(n=15)$ & \multicolumn{2}{|c|}{$0 / 15$} & \multicolumn{2}{|c|}{0} \\
\hline $\begin{array}{l}\text { Lymphomatoid papulosis } \\
(n=18)\end{array}$ & \multicolumn{2}{|c|}{$0 / 18$} & \multicolumn{2}{|c|}{0} \\
\hline
\end{tabular}

FC, flow cytometry; WB, Western blot analysis; IHC, immunohistochemistry; HD, Hodgkin's disease; ALK, anaplastic lymphoma kinase; ALCL, anaplastic large-cell lymphoma.

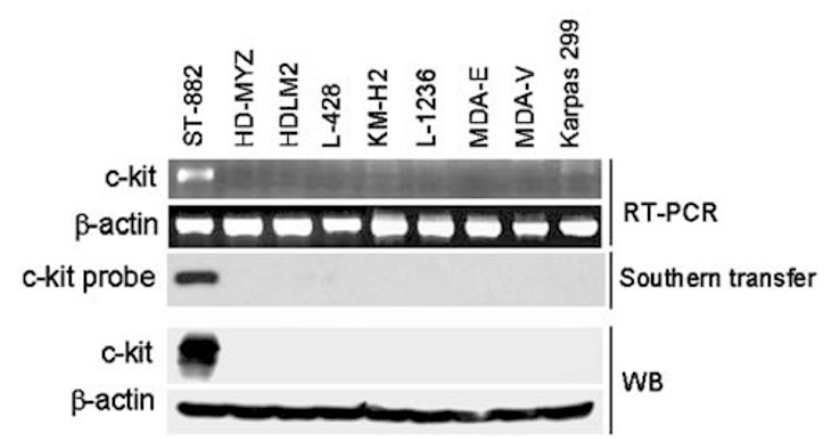

Figure 1 Top panel: Expression of c-kit mRNA in HD and ALCL cell lines as detected by RT-PCR using a set of primers we designed. cDNA from the gastrointestinal stromal tumor cell line, ST-882, served as a positive control. Southern blot transfer of RT-PCR products and hybridization with a c-kit-specific probe showed hybridization only for the control ST-882 cells. Bottom panel: Immunoblots showing expression of c-kit protein in HD and ALCL cell lines. All HD and ALCL cell lines tested were negative for c-kit. A $145 \mathrm{kDa}$ band corresponding to c-kit receptor was detected only in the ST-882 control cells. $\beta$-Actin served as a control of protein load and integrity.

gastrointestinal stromal tumor cell line (positive control) showed hybridization of appropriately sized products. 

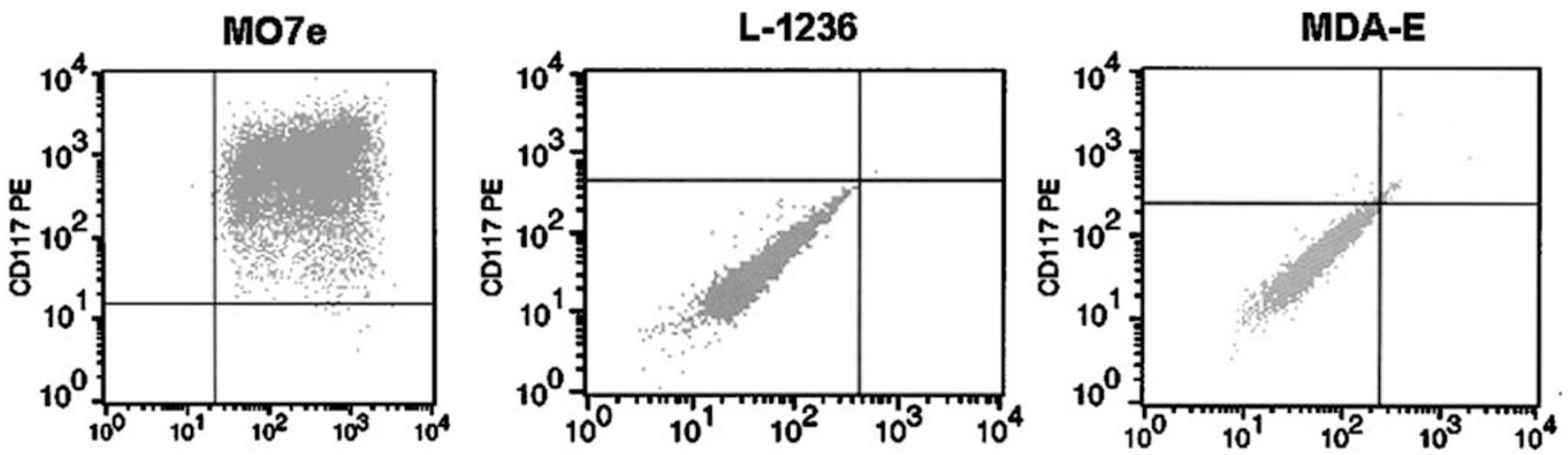

Figure 2 Representative examples of the flow cytometry immunophenotypic analysis of c-kit expression using a phycoerythrinconjugated monoclonal antibody specific for c-kit. Results from two HD cell lines, L-1236 and MDA-V, are shown; both cell lines are negative for c-kit. The MO7e cell line served as a positive control for c-kit expression in these experiments.
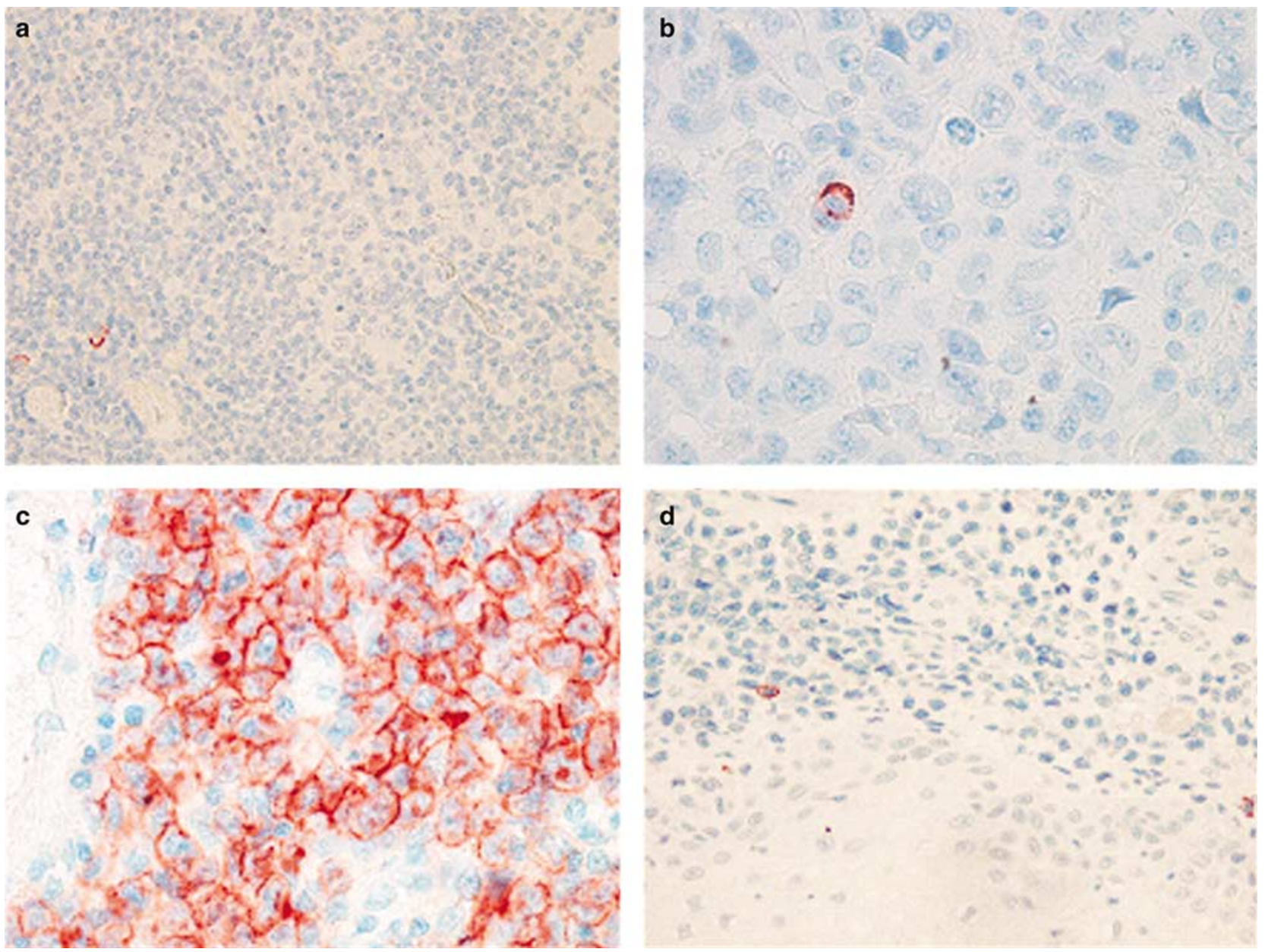

Figure 3 (a, b) Representative cases of classical HD (a), and ALK-positive ALCL (b) showing no evidence of c-kit immunoreactivity in tumor cells. Occasional monocytes or mast cells are positive for c-kit receptor and served as internal positive controls. (c) The only c-kitpositive ALK-negative ALCL tumor is shown. The tumor cells have a predominantly membranous staining pattern. (d) A representative case of primary cutaneous ALCL negative for c-kit receptor (a, d: $\times 200 ; \mathbf{b}, \mathbf{c}: \times 400$, immunoperoxidase with hematoxylin counterstain).

\section{c-kit Protein Expression in HD and ALCL Cell Lines}

Using Western blot analysis, no evidence of c-kit protein was detected in all seven HD and five ALCL cell lines tested (Table 1, Figure 1). These results were further confirmed by immunohistochemistry using cell blocks prepared from these cell lines and a polyclonal antibody reactive with c-kit ${ }^{22,23}$ 
(Table 1). We also studied seven HD and one ALCL (Karpas 299) cell lines using a monoclonal antibody specific for c-kit and flow cytometry immunophenotypic methods; all cell lines were negative (Table 1, Figure 2).

\section{c-kit Protein Expression in CD30 + Lymphomas}

Using immunohistochemical methods, c-kit was not expressed in the Hodgkin and Reed-Sternberg (HRS) cells of all 87 classical HD tumors (Figure 3a). Similarly, c-kit was negative in all 30 ALK-positive ALCL tumors (Figures $3 \mathrm{~b}$ ) and all cases of cutaneous ALCL $(n=15)$ and lymphomatoid papulosis $(n=18)$ (Figures 3d). One of 33 (3\%) ALK-negative ALCL tumors expressed c-kit with a predominantly membranous pattern of staining (Figure 3c). In summary, only one of $183(0.5 \%)$ lesions was positive.

\section{Effect of Imatinib Treatment on ALCL Cells}

Treatment of two ALCL cell lines, Karpas 299 and SUDHL-1, with different concentrations of imatinib did not affect cell proliferation or viability using the MTS assay as shown in Figure 4. The graph showing the response of ALCL cell lines to different concentrations of imatinib was generated with the results obtained at 24 and $48 \mathrm{~h}$ after treatment in two different experiments. Untreated Karpas 299 and SUDHL-1 cells served as a control for the baseline levels of cell proliferation and viability. Similarly, treatment of three HD cell lines, L-428, HD-LM2, and HD-MyZ, did not affect cell proliferation or viability assessed using the MTS assay (data not shown). The MO7e cell line was used as a positive control, as shown previously by others. ${ }^{11}$

Annexin V/PI staining revealed no difference in apoptosis of ALCL and HD cells treated with different concentrations of imatinib compared with control cells (Figure 5).

\section{Discussion}

This report provides in vivo and in vitro evidence that c-kit is not expressed at the RNA or protein level in HD and ALK-positive ALCL cell lines and tumors. In cell lines, we used an RT-PCR method to amplify c-kit mRNA and confirmed the results by Southern blot transfer and hybridization with a c-kit specific probe. We also utilized a variety of methods to assess c-kit protein including flow cytometry, Western blot analysis and immunohistochemical techniques. In 165 CD30 + lymphomas and 18 cases of lymphomatoid papulosis, we showed c-kit expression using immunohistochemical methods in only one $(0.5 \%)$ case, an ALK-negative ALCL tumor that showed a typical membranous staining pattern for c-kit (Figure 3c).
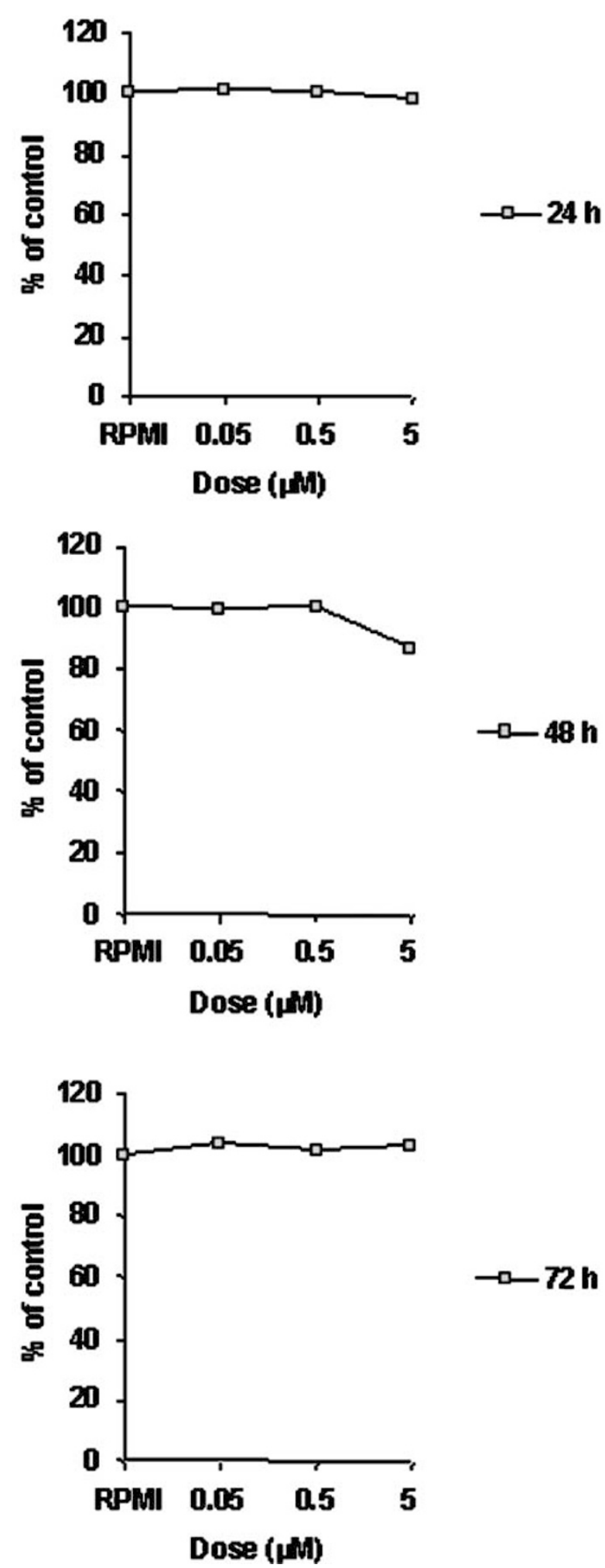

Figure 4 Proliferation of SUDHL-1 cells was determined using the MTS assay over a 72-h time course. The graphs represent the proliferation of viable SUDHL-1 cells treated with different concentrations of imatinib $(0.05,0.5$ and $5 \mu \mathrm{M})$ compared with untreated cells. MTS-positive cells were counted at 24, 48 and $72 \mathrm{~h}$. The curves show the percentage of viable cells (y-axis) and doses ( $x$-axis). Untreated SUDHL-1 cells are designated as RPMI only. 

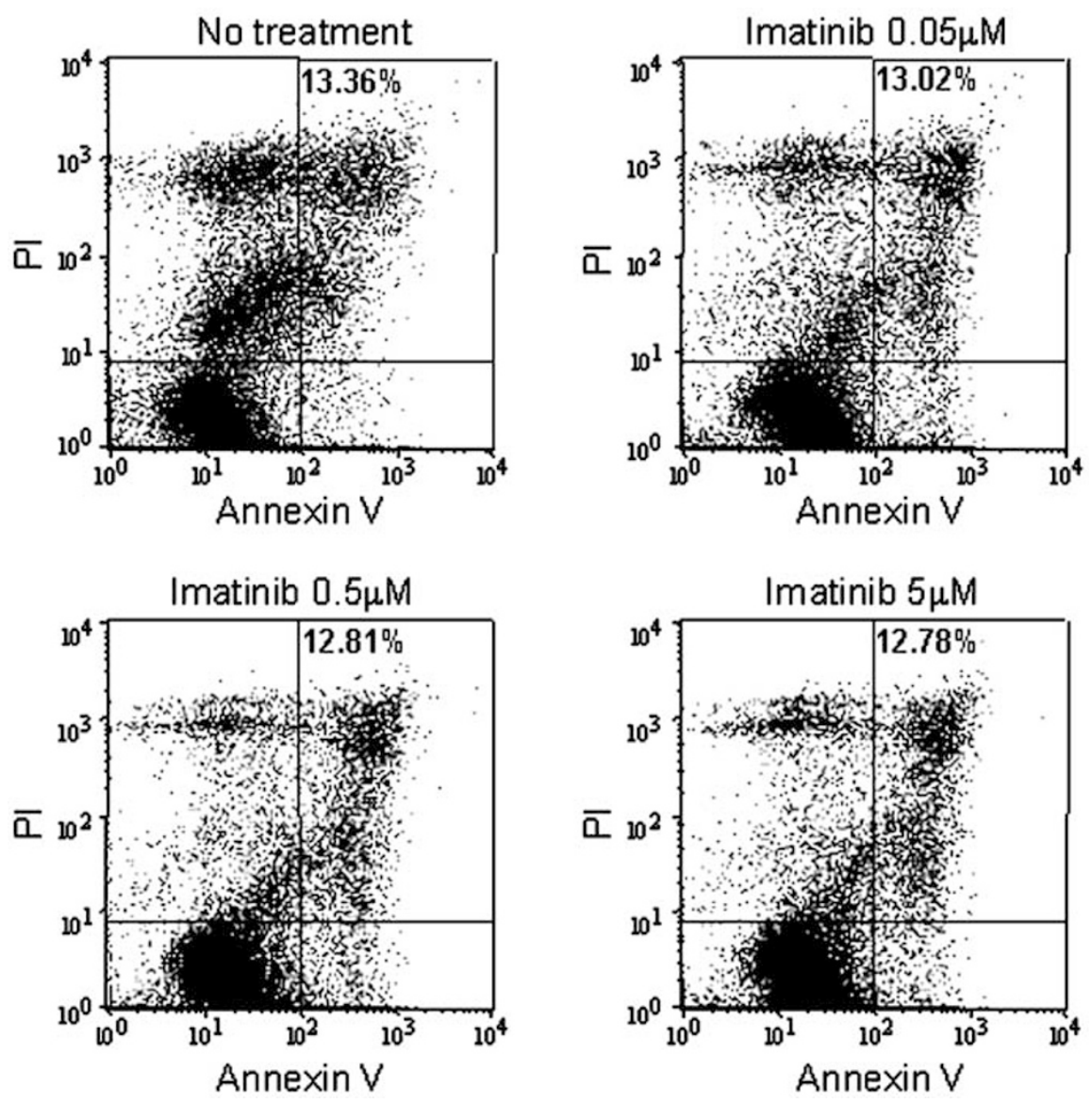

Figure 5 Apoptosis of SUDHL-1 cells treated with different concentrations of imatinib was assessed using annexin V/PI staining and flow cytometry. The fraction of annexin V-positive SUDHL-1 cells was 13.36\% before treatment and 13.02, 12.81, and 12.78\% after treatment with imatinib at concentrations of $0.05,0.5$ and $5 \mu \mathrm{M}$, respectively.

The data presented here extend the results of a preliminary study from our institution that included only ALK-positive ALCL tumors and a smaller number of HD tumors. ${ }^{12}$ Our findings are also in agreement with two recent reports that demonstrated no evidence of c-kit immunoreactivity in a total of $32 \mathrm{HD}$ tumors. ${ }^{10,11}$ These results and our data are contrary to those of Pinto et $\mathrm{al}^{7}$ who found c-kit expression in fresh-frozen sections of 11 of 16 ALCL and 11 of $21 \mathrm{HD}$ tumors. Subsequently, the same group reported that five of six HD cell lines expressed functional c-kit receptor. ${ }^{8}$ In both studies, the authors used the 17F11 monoclonal antibody that recognizes an extracellular domain of c-kit. The 17F11 antibody was raised by immunization of a Balb/c mouse with leukemic blasts from a patient with acute non-lymphocytic leukemia and was reported to react positively with most leukemic blasts of myeloid, but not lymphoid, lineage. The authors reported that $17 \mathrm{~F} 11$ specifically recognized the c-kit gene product in NIH-3T3 fibroblasts transfected with the human c-kit gene. ${ }^{24}$ However, subsequent functional studies showed that the corresponding epitope of 17F11 was not competing for stem cell factor (SCF), the c-kit ligand-binding site. ${ }^{25}$ The 17F11 antibody is no longer commer- cially available and we could not test its immunoreactivity in this study.

Our data, showing absence of c-kit expression in HD and ALCL cell lines, are supported, in part, by a recent preclinical study by Re et al. ${ }^{11}$ They reported that only one of six HD cell lines tested, the L-1236 cell line, was positive for c-kit by flow cytometry. We also demonstrate here that treatment with different doses of imatinib did not affect proliferation or viability of two ALCL and three HD cell lines (Figure 4). Annexin V/7-AAD staining also confirmed that HD and ALCL cells treated with imatinib do not undergo chemotherapy-induced apoptosis (Figure 5). Our data are supported by the results of two other studies. Re et $a l^{11}$ showed that the proliferation of L-1236 cells was not influenced by stimulation with SCF, anti-SCF antibody, or imatinib. Ergin et $a{ }^{26}$ demonstrated that imatinib had only a minimal effect on apoptosis of three ALCL cell lines (Karpas 299, SUPM2, and SU-DHL-1).

The explanation for the remarkable discrepancy between the studies of Pinto et $a l^{7}$ and Aldinucci and colleagues ${ }^{8,9}$ with our data regarding c-kit expression in HD and ALCL is uncertain. However, a cross reaction of the $17 \mathrm{~F} 11$ antibody with an unrelated epitope cannot be excluded, since the 
results obtained using this antibody have not been confirmed using other commercially available antibodies. In addition, independent work from others using immunohistochemical methods with widely used antibodies failed to show c-kit expression in the HRS cells of HD. ${ }^{10,11}$ At the RNA level, Aldinucci et $a l^{8}$ have reported that c-kit RNA is detected in HD-derived cell lines. We also tested the primers and RT-PCR conditions as described in their study. ${ }^{8}$ Although we observed multiple RT-PCR products in ethidium-stained gels using the HD and ALCL cell lines we tested, following Southern blot transfer and hybridization with a specific c-kit probe there was no hybridization (data not shown). Thus, we believe that these RT-PCR products are likely to be nonspecific.

We conclude that c-kit RNA and protein are consistently not expressed in HD and ALK-positive ALCL cell lines and tumors or in cutaneous ALCL tumors and that c-kit is only rarely $(<5 \%)$ expressed in ALK-negative ALCL tumors. All cases of lymphomatoid papulosis were also negative for c-kit. In addition, imatinib does not seem to be active in HD and ALCL in vitro. These findings suggest that c-kit is probably not an appropriate target for therapeutic agents such as imatinib in the treatment of patients with HD and ALCL.

\section{Acknowledgement}

We thank Dr J Trent who kindly provided us with the ST-882 cell line (positive control for c-kit expression) and imatinib.

\section{References}

1 Yarden Y, Kuang WJ, Yang-Feng T, et al. Human protooncogene c-kit: a new cell surface receptor tyrosine kinase for an unidentified ligand. EMBO J 1987;6: 3341-3351.

2 Huang E, Nocka K, Beier DR, et al. The hematopoietic growth factor KL is encoded by the SL locus and is the ligand of the c-kit receptor and the gene product of the W locus. Cell 1990;63:225-233.

3 Scheijen B, Griffin JD. Tyrosine kinase oncogenes in normal hematopoiesis and hematological disease. Oncogene 2002;21:3314-3333.

4 Lyman SD, Jacobsen SE. c-kit ligand and Flt3 ligand: stem/progenitor cell factors with overlapping yet distinct activities. Blood 1998;91:1101-1134.

5 Andre C, d'Auriol L, Lacombe C, et al. c-kit mRNA expression in human and murine hematopoietic cell lines. Oncogene 1989;4:1047-1049.

6 Morita S, Tsuchiya S, Fujie H, et al. Cell surface c-kit receptors in human leukemia cell lines and pediatric leukemia: selective preservation of c-kit expression on megakaryoblastic cell lines during adaptation to in vitro culture. Leukemia 1996;10:102-105.

7 Pinto A, Gloghini A, Gattei V, et al. Expression of the c-kit receptor in human lymphomas is restricted to
Hodgkin disease and CD30+ anaplastic large cell lymphomas. Blood 1994;83:785-792.

8 Aldinucci D, Poletto D, Nanni P, et al. Hodgkin and Reed-Sternberg cells express functional c-kit receptors and interact with primary fibroblasts from Hodgkin's disease-involved lymph nodes through soluble and membrane-bound stem cell factor. Br J Haematol 2002; 118:1055-1064.

9 Aldinucci D, Gattei V. The role of interleukin-3 and stem cell factor in classical Hodgkin's disease. Blood 2003;101:376-377.

10 Natkunam Y, Rouse RV. Utility of paraffin section immunohistochemistry for C-KIT (CD117) in the differential diagnosis of systemic mast cell disease involving the bone marrow. Am J Surg Pathol 2000;24: 81-91.

11 Re D, Wickenhauser C, Ahmadi T, et al. Preclinical evaluation of the antiproliferative potential of STI571 in Hodgkin's disease. Br J Cancer 2002;86: 1333-1335.

12 Rassidakis GZ, Georgakis GV, Younes A, et al. c-kit is not expressed in Hodgkin disease and anaplastic lymphoma kinase (ALK)-positive anaplastic large cell lymphoma. Blood 2003;102:4619-4620.

13 Buchdunger E, Zimmermann J, Mett H, et al. Inhibition of the Abl protein-tyrosine kinase in vitro and in vivo by a 2-phenylaminopyrimidine derivative. Cancer Res 1996;56:100-104.

14 Druker BJ, Tamura S, Buchdunger E, et al. Effects of a selective inhibitor of the Abl tyrosine kinase on the growth of Bcr-Abl positive cells. Nat Med 1996;2: 561-566.

15 Druker BJ, Sawyers CL, Kantarjian H, et al. Activity of a specific inhibitor of the BCR-ABL tyrosine kinase in the blast crisis of chronic myeloid leukemia and acute lymphoblastic leukemia with the Philadelphia chromosome. N Engl J Med 2001;344: 1038-1042.

16 Heinrich MC, Griffith DJ, Druker BJ, et al. Inhibition of c-kit receptor tyrosine kinase activity by STI 571, a selective tyrosine kinase inhibitor. Blood 2000;96: 925-932.

17 Buchdunger E, O’Reilly T, Wood J. Pharmacology of imatinib (STI571). Eur J Cancer 2002;38(Suppl 5): S28-S36.

18 van Oosterom AT, Judson I, Verweij J, et al. Safety and efficacy of imatinib (STI571) in metastatic gastrointestinal stromal tumours: a phase I study. Lancet 2001;358:1421-1423.

19 Delsol G, Ralfkiaer E, Stein H, et al. Anaplastic large cell lymphoma, In: Jaffe ES, Harris NL, Stein H, Vardiman JW (eds). Pathology and Genetics of Tumors of Haematopoietic and Lymphoid Tissues World Health Organization Classification of Tumours Lyon, IARC Press: France, 2001, pp 230-235.

20 Rassidakis GZ, Jones D, Thomaides A, et al. Apoptotic rate in peripheral T-cell lymphomas: a study using a tissue microarray with validation on full tissue sections. Am J Clin Pathol 2002;118:328-334.

21 Rassidakis GZ, Sarris AH, Herling M, et al. Differential expression of BCL-2 family proteins in ALK-positive and ALK-negative anaplastic large cell lymphoma of T/null-cell lineage. Am J Pathol 2001;159:527-535.

22 Lucas DR, al-Abbadi M, Tabaczka P, et al. c-Kit expression in desmoid fibromatosis. Comparative immunohistochemical evaluation of two commercial antibodies. Am J Clin Pathol 2003;119:339-345. 
23 Hornick JL, Fletcher CD. Validating immunohistochemical staining for KIT (CD117). Am J Clin Pathol 2003;119:325-327.

24 Buhring HJ, Ullrich A, Schaudt K, et al. The product of the proto-oncogene c-kit (P145c-kit) is a human bone marrow surface antigen of hemopoietic precursor cells which is expressed on a subset of acute non-lymphoblastic leukemic cells. Leukemia 1991;5: 854-860.
25 Ashman LK, Buhring HJ, Aylett GW, et al. Epitope mapping and functional studies with three monoclonal antibodies to the c-kit receptor tyrosine kinase, YB5.B8, 17F11, and SR-1. J Cell Physiol 1994;158:545-554.

26 Ergin M, Denning MF, Izban KF, et al. Inhibition of tyrosine kinase activity induces caspase-dependent apoptosis in anaplastic large cell lymphoma with NPM-ALK (p80) fusion protein. Exp Hematol 2001; 29:1082-1090. 